\title{
Complex Characteristics of Multichannel Household Appliance Supply Chain with the Price Competition
}

\author{
Junhai Ma and Wandong Lou \\ College of Management and Economics, Tianjin University, Tianjin 300072, China \\ Correspondence should be addressed to Wandong Lou; wd1160211@126.com
}

Received 16 November 2016; Accepted 16 January 2017; Published 13 March 2017

Academic Editor: Vladimir Modrak

Copyright ( 2017 Junhai Ma and Wandong Lou. This is an open access article distributed under the Creative Commons Attribution License, which permits unrestricted use, distribution, and reproduction in any medium, provided the original work is properly cited.

\begin{abstract}
This paper studies the complex characteristics caused by the price competition in multichannel household appliance supply chains. We consider a two-level household appliance supply chain system consisting of a manufacturer with an Internet channel and a retailer with a traditional channel and an Internet channel. Each channel's price-setting follows the bounded rational decision process in order to obtain the optimal profit or more market share. Considering that the price competition often leads to the demand and order fluctuation, we also investigate the bullwhip effect of the multichannel supply chains on the basis of the orderup-to-inventory policy. From the numerical simulation, we find a system in a chaotic state will suffer larger bullwhip effect than a stable system, and the manufacturer's Internet channel is helpful to mitigate the bullwhip effect. Our results provide some useful managerial inspirations for the household manufacturer and retailers. Firstly, each channel should make their retail price with a suitable price adjustment speed in the stable region, and each time pricing cannot exceed the domain of attraction. Secondly, the manufacturer can adopt a more radical pricing strategy in their Internet channel to mitigate the bullwhip effect. Thirdly, the price adjustment should be reviewed and be appropriately reduced if the price adjustment is too large.
\end{abstract}

\section{Introduction}

With the widespread e-commerce and the increasingly fierce competition all over the world, more and more manufacturers and traditional retail firms open up the Internet supply channel as an important means to expand the market. In China, as of December 2015, the size of netizens reached 688 million, including 413 million online shopping users whose ratio had got up to $60 \%$. In the first half of 2016 , the scale of Chinese online retail sales accounted for $14.8 \%$ of social total retail sales. For Chinese household appliances market, the manufacturer firstly formed the direct retail channel on the Internet via opening up an independent network platform or setting up flagship stores on the popular network shopping platform, such as Tmall and JD. Compared with the traditional retail channel, the manufacturer direct retail channel can cut cost and provide a lower price to the customers. In order to dominate the market with a big share, many traditional retailers such as GOME and Suning also construct the network channel, cooperating with their traditional retail channels [1].
In this paper, we focus on a household appliance supply chain, which is composed of a manufacturer with an Internet channel and a retailer with a traditional channel and an Internet channel. The coordination of the manufacturer and retailer in a dual-channel supply chain has been analyzed for many times. [2-4]. The price competition between the manufacturer's Internet channel and the retailer's multichannels has become a common and significant issue in supply chain management. In order to gain much more profit and marker share, retailer and other supply chain firms which distribute the substitute products often lower their price as much as possible to compete with the opponent channels. Unfortunately, the price variability is the main cause of bullwhip effect (BWE) and leads to the demand variability which causes bullwhip effect [5].

In the recent two years, the channel selection and strategy in multichannel supply chain have become a research hotspot. Melis et al. [6] investigated the impact of the multichannel retail mix on online store choice from the perspective of the online experience. Their results show that multichannel shoppers, at the start of online grocery shopping, tended to select 
the online store belonging to the same chain as their preferred offline store. When the online grocery shopping experience increased, the multichannel shoppers' focus shifted from a comparison within a chain across channels to a comparison across chains within the online channel. Liu et al. [7] studied channel choice decisions in a multichannel supply chain under a strategy where there was an ex ante commitment made on the retail price markup. They assumed the market demand was uncertain and dependent on the price and sales efforts. They found that the manufacturer would increase inventory quantity for direct sales when the retail price rose, and the increase in demand fluctuation only affected the degree of channel preference but did not change the manufacturer's channel choice. They thought adding a direct channel was a marketing strategy, rather than a competitor of the retail channel, and could help the supply chain expand the market demand. Wang et al. [1] investigated the channel selection in a supply chain with a multichannel retailer, from the role of channel operating costs. They established a linear demand model to explore the channel selection and pricing strategy in a multichannel supply chain and found that the gap between the online and offline channels' operating costs was critical to the retailer's choice of its channel selection strategy. They thought that small product differentiation was more favorable to the manufacturer in a retailer-lead supply chain and the manufacturer could benefit from a rise in the wholesale price and increasing demand in the retail channel.

Most of the research on the coordination of multichannel supply chain is based on the condition of complete information or the complete rationality. However, the retail channels cannot get all the information about their consumers. They can make price decision based on the limited information and experience and have to make dynamic game with the opponents in the market. In recent years, several scholars have studied dual-channel supply chain based on the application of bounded rationality and complex dynamics. Li and $\mathrm{Ma}$ [8] analyzed the complexity of the dual-channel supply chain system with delay decision. Ma and Xie [9] gave a comparison and complex analysis on dual-channel supply chain under different channel power structures and uncertain demand.

Most of the existing literatures on multichannel supply chain or supply chain management focus on the impact of the price game on the profit. In fact, the order and inventory of the supply chain are also affected by the price competition. Because the price variability is one of the major causes of the bullwhip effect, the price-sensitive demand streams have also been a common model in the research on bullwhip effect [7, 10-12]. Ma et al. [13] proposed an analytical framework that incorporates two parallel supply chains interacting price-sensitive demands and explored their interactions to determine the bullwhip effect.

However, the existing research work does not demonstrate the complex characteristics of multichannel household appliance supply chain when there are price competitions among the channels in the dynamics system. Instead, we investigate the price making process of the traditional and Internet channels and the BWE of the whole supply chain. In this paper, we consider a two-level household appliance supply chain system consisting of a manufacturer with an
Internet channel and a retailer with a traditional channel and an Internet channel. In practice, many household appliance supply chain systems meet the premise of our model; for instance, in Chinese market, Haier, Midea, and Gree, are famous household appliance firms. They all market their products via the large retail chain enterprises, such as GOME, Suning, and their own Internet direct sales channel. The retailers make pricing decisions affected not only by the wholesale price but also by the price of the manufacturer's direct channel.

The objective of our research is to investigate the complex dynamics characteristics of the multichannel price game system and the bullwhip effect in the household appliance supply chain management. On the basis of the assumption that both retailers employ the order-up-to-inventory policy and the bounded rational price forecasting method, we investigate how the bullwhip effect is affected by the pricing strategy in multichannel supply chains with price-sensitive demands.

This study contributes to the existing retailing and multichannel literature in several ways. To the best of our knowledge, we are the first to systematically investigate the complex characteristics of a multichannel household appliance supply chain and the bullwhip effect of the whole supply chain affected by the interaction coming from the channel price adjustment. From a managerial point of view, our results provide useful insights for the household manufacturer who operates an Internet retail channel and retailers who have adopted a multichannel strategy. More specifically, our research provides the following: (i) the household appliance manufacturer and its retailer should manage their retail channel with a suitable price adjustment speed in the stable region, and each of their pricing decisions cannot exceed the domain of attraction. (ii) A greater speed adjustment of the manufacturer's Internet channel is helpful to mitigate the bullwhip effect. (iii) The feedback control on the retailer's Internet channel is an effective method to control the chaos of price game system and mitigate the bullwhip effect of the supply chain.

This paper is organized as follows. In Section 2 we describe the problem and construct the model of the multichannel supply chains. Section 3 analyzes the complexity of the supply chain system; then, in Section 4, we investigate the bullwhip effect and the impact of the price adjustment speeds through the numerical simulation. The feedback control method is used in the system to control the chaos and the BWE, in Section 5. Finally, Section 6 represents the conclusions and insights of this study.

\section{The Model}

2.1. Assumptions. The supply chain model is based on the following assumptions:

(a) The system constructs multichannel supply chains including a household appliance manufacturer with an Internet channel and a retailer with a traditional channel and its Internet channel. 


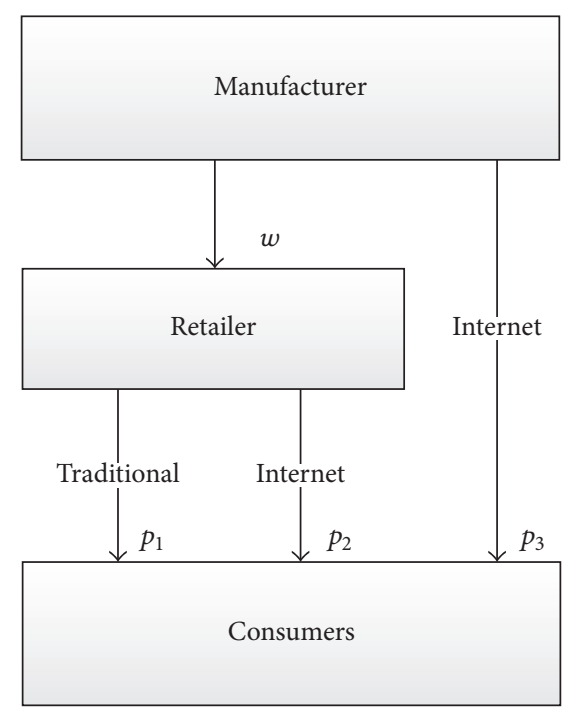

FIGURE 1: The supply chain model with Internet channel.

(b) The bounded rational retailer and the manufacturer sell homogeneous product to the same market on the basis of price competition.

(c) Every channel of the supply chains could only get partial market information about the market and its rivals and makes price decision with the bounded rationality expectation.

(d) All channels employ the order-up-to-inventory policy with different lead time. The retailer's two channels have longer lead time than that of the manufacturer.

(e) The market's demand for the product is equal to every channel's sales volume.

(f) The manufacturer $(\mathrm{M})$ determines the wholesale price $w$ to the retailer (R) while the retailer's two channels set their prices according the wholesale price, respectively.

2.2. Note Expression. In practice, firms of supply chain, no matter the manufacturer or the retailer, can give an estimate about every parameter appeared in the following model. The unit cost of the product is the basic manufacturing cost elements of firms. The wholesale price $w$ is usually determined by the contract signed by both the manufacturer and retailer. Under normal circumstances, firms of household appliance supply chain can obtain information about the parameters from their financial statements. For ease of reference, the notations of the key parameters as well as their meaning are listed in Key Notations.

2.3. Model Construction. We consider a two two-echelon supply chains system consisting of a manufacturer and a retailer with dual-channel. As shown by Figure 1, channel 1 is the retailer's traditional retail channel; channel 2 is the Internet channel operated by retailer and channel 3 is the Internet channel of the manufacturer.
In the physical channel, the manufacturer distributes the products to the retailer with the unit wholesale price $w$ and retails similar products through the network direct sales channel with the unit price of $p_{3}$. According to the wholesale price and the price of the manufacturer's direct channel, the retailer sells the products in its physical channel and network platform, with the unit price of $p_{1}$ and $p_{2}$, respectively. Generally, the customers are price-sensitive and consider the comparison of every channel's price and nonprice factors to make purchase decisions. The demand functions of the traditional and Internet channel can be written as

$$
\begin{aligned}
d_{1}= & \delta_{1} a+\varepsilon_{1}-b_{1} p_{1}+\beta\left(p_{2}-p_{1}\right)+\gamma\left(p_{3}-p_{1}\right), \\
d_{2}= & \delta_{2} a+\varepsilon_{2}+\beta\left(p_{1}-p_{2}\right)-b_{2} p_{2}+\eta\left(p_{3}-p_{2}\right), \\
d_{3}= & \left(1-\delta_{1}-\delta_{2}\right) a+\varepsilon_{3}+\gamma\left(p_{1}-p_{3}\right)+\eta\left(p_{2}-p_{3}\right) \\
& -b_{3} p_{3} .
\end{aligned}
$$

The parameter $a(a>0)$ represents the possible largest demand; $\delta_{1}$ is the potential market share of traditional channel; $\delta_{2}$ is the potential market share of the retailer's Internet channel. The customer's possible largest market demand of every channel is uncertain and affected by factor $\varepsilon_{i}, i=1,2,3 . \varepsilon_{i}$ follows normal distribution; its mean is zero; the variance is $\sigma_{i}, i=1,2.1-\delta_{1}-\delta_{2}$ is the market share of the manufacturer's Internet channel $\left(0<\delta_{i}<1\right.$, $i=1,2,3) . b_{i}$ denotes the price-sensitivity coefficient of the product; $\gamma, \beta, \eta$ are the substitutability coefficients of the channel $i$ and $p_{i}$ is the sales price of channel $i$. This means that each channel has their loyal customers. Here, we denote by $d_{i}$ the market demand of the first retailer while we will denote by $p_{i}$ the prices at time $t$ of channel $i$. We assume that retailer wholesales products from the manufacturer in accordance with the wholesale price $w$ and sells products to customers through the traditional retail channel and its Internet channel, respectively.

The expected profit function of manufacturers and retailers in dual-channel supply chain can be expressed as follows:

$$
\begin{aligned}
& \pi_{1}=d_{1}\left(p_{1}-w\right), \\
& \pi_{2}=d_{2}\left(p_{2}-w\right), \\
& \pi_{3}=d_{3}\left(p_{3}-c\right)+\left(d_{1}+d_{2}\right)(w-c) .
\end{aligned}
$$

In Chinese household appliance market, brick-andmortar store is the traditional channel of the manufacturer. With the development of the Internet economics, many household appliance manufacturers, for instance, Haier and Midea, open up their online channels to sell products directly. In recent years, some household appliance chain stores, for instance, Suning and GOME, set up online sales channel; they not only chase profit, but also compete for market share with the manufacturers on the online channel. The retailer's international channel seeks the profit, and, meanwhile, it takes the market share as an important aim of their channel. 
Their utility functions based on the profit and the market share are as follows:

$$
\begin{aligned}
& u_{1}=\pi_{1}, \\
& u_{2}=v \pi_{2}+(1-v) e_{2}, \\
& u_{3}=\pi_{3} .
\end{aligned}
$$

Here, $v$ is the parameter of the preference for the profit. $e_{2}$ is the market share of the retailer's Internet channel (channel 2).

All channel's marginal utilities can be written as follows (see the appendix):

$$
\begin{aligned}
\frac{\partial u_{1}}{\partial p_{1}}= & a \delta_{1}+p_{2} \beta+p_{3} \gamma-2 p_{1}\left(\beta+\gamma+\theta_{1}\right) \\
& +w\left(\beta+\gamma+\theta_{1}\right), \\
\frac{\partial u_{2}}{\partial p_{2}}= & a \delta_{2}+p_{1} \beta+p_{3} \eta-2 p_{2}\left(\beta+\eta+\theta_{2}\right) \\
& +v w\left(\beta+\eta+\theta_{2}\right), \\
\frac{\partial u_{3}}{\partial p_{3}}= & a\left(1-\delta_{1}-\delta_{2}\right)+p_{1} \gamma+p_{2} \eta-2 p_{3}\left(\gamma+\eta+\theta_{3}\right) \\
& +w(\gamma+\eta)+c \theta_{3} .
\end{aligned}
$$

2.4. Decision-Making Mechanism. From a long-term perspective, the price game among the multiple channels is a dynamical process. Each channel will adjust their retail price timely on the basis of their marginal utilities and current prices. However, in the actual market environment, each household appliance retail channel can only get partial information about their competitors. Therefore, we assume the retailer and the manufacturer are both bounded rational and they set prices with bounded rational expectations. That is to say, the next period retail price of channel $i$ is determined by the current price and marginal utility [14, 15]. From the view of channel 1 , when the marginal utility is positive $\left(\partial u_{1} / \partial p_{1}>0\right)$, the increase of the traditional retail price will benefit the retailer. So the next period price of the retailer's traditional channel $p_{1, t}$ should increase $\alpha_{i} p_{i, t}\left(\partial u_{i, t} / \partial p_{i}\right)$ on the basis of $p_{1}(t)$.

Their dynamic pricing strategies are as follows:

$$
p_{i, t+1}=p_{i, t}+\alpha_{i} p_{i, t} \frac{\partial u_{i, t}}{\partial p_{i}}, \quad i=1,2,3
$$

$\alpha_{i}(\geq 0)$ is the price adjustment parameter of channel $i(i=1,2,3)$. Their value depends on the power of the retail channel chasing greater utility. A large adjustment parameter means the retailer wants to get the maximum utility as soon as possible. Meanwhile, this channel should have stronger ability to regulate and control the prices.

According to (4) and (5), we can get a multichannel competitive discrete dynamic system:

$$
\begin{aligned}
& p_{1, t+1}=p_{1, t}+\alpha_{1} p_{1, t}\left(a \delta_{1}+p_{2, t} \beta+p_{3, t} \gamma\right. \\
& \left.-2 p_{1, t}\left(\beta+\gamma+\theta_{1}\right)+w\left(\beta+\gamma+\theta_{1}\right)\right), \\
& p_{2, t+1}=p_{2, t}+\alpha_{2} p_{2, t}\left(a \delta_{2}+p_{1, t} \beta+p_{3, t} \eta\right. \\
& \left.\quad-2 p_{2, t}\left(\beta+\eta+\theta_{2}\right)+v w\left(\beta+\eta+\theta_{2}\right)\right), \\
& p_{3, t+1}=p_{3, t}+\alpha_{3} p_{3, t}\left(a\left(1-\delta_{1}-\delta_{2}\right)+p_{1, t} \gamma+p_{2, t} \eta\right. \\
& \left.-2 p_{3, t}\left(\gamma+\eta+\theta_{3}\right)+w(\gamma+\eta)+c \theta_{3}\right) .
\end{aligned}
$$

\section{System Analysis of the Multichannel Supply Chains}

3.1. Equilibrium Solutions. In system (6), we let $p_{i, t+1}=$ $p_{i, t}(i=1,2,3)$;

$$
\begin{aligned}
& \alpha_{1} p_{1, t}\left(a \delta_{1}+p_{2, t} \beta+p_{3, t} \gamma-2 p_{1, t}\left(\beta+\gamma+\theta_{1}\right)\right. \\
& \left.\quad+w\left(\beta+\gamma+\theta_{1}\right)\right)=0, \\
& \alpha_{2} p_{2, t}\left(a \delta_{2}+p_{1, t} \beta+p_{3, t} \eta-2 p_{2, t}\left(\beta+\eta+\theta_{2}\right)\right. \\
& \left.\quad+v w\left(\beta+\eta+\theta_{2}\right)\right)=0, \\
& \alpha_{3} p_{3, t}\left(a\left(1-\delta_{1}-\delta_{2}\right)+p_{1, t} \gamma+p_{2, t} \eta\right. \\
& \left.\quad-2 p_{3, t}\left(\gamma+\eta+\theta_{3}\right)+w(\gamma+\eta)+c \theta_{3}\right)=0 .
\end{aligned}
$$

We can get at most eight fixed points. According to the actual household appliance supply chains in China, we set values to some parameters of the system before we solve (7). Let $a=4, c=1, w=1.1, v=0.5, \theta_{1}=0.6, \theta_{2}=0.6, \theta_{3}=$ $0.6, \delta_{1}=0.4, \delta_{2}=0.35, \eta=0.2, \gamma=0.1$, and $\beta=0.1$ in the following sections, unless otherwise specified. Then the eight equilibrium solutions of system can be expressed as follows: $E_{1}=(0,0,0), E_{2}=(0,0,1.1375), E_{3}=(0,1.05278$, $0), E_{4}=(1.43889,0,0), E_{5}=(0,1.11986,1.20749), E_{6}=$ $(1.5073,0,1.2317), E_{7}=(1.5753,1.2278,0)$, and $E_{8}=(1.658$, $1.3105,1.32303)$.

The fixed points $E_{k}(k=1,2,3,4,5,6,7)$ are all boundary equilibrium, and $E_{8}$ is the Nash equilibrium.

3.2. Stability Analysis. In order to analyze the stability of the equilibrium point, we firstly calculate the Jacobian matrix system (6):

$$
\begin{aligned}
J(E)= & \left(\begin{array}{lll}
j_{11} & j_{12} & j_{13} \\
j_{21} & j_{22} & j_{23} \\
j_{31} & j_{32} & j_{33}
\end{array}\right), \\
j_{11}= & 1+a \alpha_{1} \delta_{1}+p_{2} \alpha_{1} \beta+p_{3} \alpha_{1} \gamma \\
& -4 p_{1} \alpha_{1}\left(\beta+\gamma+\theta_{1}\right)+w \alpha_{1}\left(\beta+\gamma+\theta_{1}\right), \\
j_{22}= & 1+a \alpha_{2} \delta_{2}+p_{1} \alpha_{2} \beta+p_{3} \alpha_{2} \eta \\
& -4 p_{2} \alpha_{2}\left(\beta+\eta+\theta_{2}\right)+v w \alpha_{2}\left(\beta+\eta+\theta_{2}\right),
\end{aligned}
$$




$$
\begin{aligned}
j_{33}= & 1+a \alpha_{3}\left(1-\delta_{1}-\delta_{2}\right)+p_{1} \alpha_{3} \gamma+p_{2} \alpha_{3} \eta \\
& -4 p_{3} \alpha_{3}\left(\gamma+\eta+\theta_{3}\right)+w \alpha_{3}(\gamma+\eta) \\
& +c \alpha_{3} \theta_{3} . \\
j_{12}= & p_{1} \alpha_{1} \beta \\
j_{13}= & p_{1} \alpha_{1} \gamma \\
j_{21}= & p_{2} \alpha_{2} \beta \\
j_{23}= & p_{2} \alpha_{2} \eta \\
j_{31}= & p_{3} \alpha_{3} \gamma \\
j_{32}= & p_{3} \alpha_{3} \eta
\end{aligned}
$$

The corresponding characteristic equation of (8) can be simplified as the following forum, according to $|J-\lambda I|=0$ :

$$
f(\lambda)=\lambda^{3}+A \lambda^{2}+B \lambda+C=0 .
$$

Jury stability criterion is the necessary and sufficient condition of asymptotic stabilization at the equilibrium point. So all parameters of system (6) should meet the following conditions in accordance with the Jury stability criterion:

$$
\begin{array}{r}
C^{2}<1, \\
1+A+B+C>0, \\
-1+A-B+C<0, \\
(A C-B)^{2}-\left(C^{2}-1\right)^{2}<0 .
\end{array}
$$

The region of stability in the 3D space of the channels' adjustment speeds is plotted in Figure 2, which represents that fixed point of system (6) is asymptotically stable with the values of $\left(\alpha_{1}, \alpha_{2}, \alpha_{3}\right)$ in this region. If the values of $\left(\alpha_{1}, \alpha_{2}, \alpha_{3}\right)$ are out of the stable region, even if only one parameter is not in the stable region, the system will lose its stability.

As shown in Figure 2, the stability region of system is determined by all three channels' adjustment speed parameters, but it is obvious that range of $\alpha_{1}$ is less than that of $\alpha_{2}$ and $\alpha_{3}$. That is to say, the adjustment speed range of the retailer's traditional channel is less than that of retailer's Internet channel and the manufacturer's Internet channel, while the two Internet channels are similar to each other from the view of the price adjustment speed.

Figure 3 shows three 2D parameter basin diagrams with respect to the two of all three parameters, when the rest one is fixed. Regions in the parameter plane converging to stable cycles of a particular period are plotted in every graph, and each color corresponds to a given period. The green is for the stable state; the orange is for two periodic cycles; the red is for four periodic cycles; and the yellow is for eight periodic cycles. Mostly, as the parameter $\alpha_{i}$ grows up from the green area passing through orange, red, and yellow areas, the system turns into chaos through flip bifurcation.

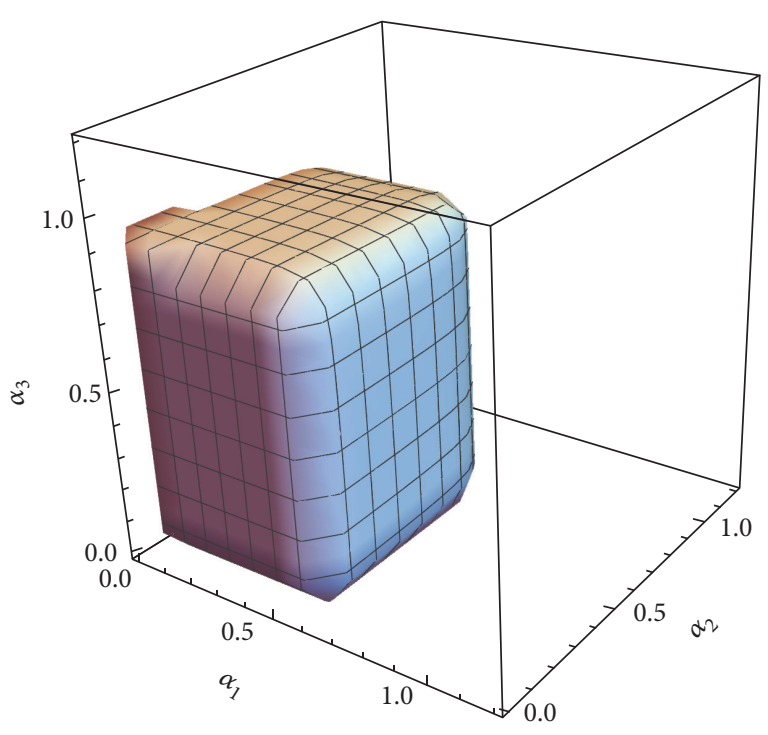

FIGURE 2: The stability region of system (6).

When $\left(\alpha_{1}, \alpha_{2}\right),\left(\alpha_{2}, \alpha_{3}\right)$, or $\left(\alpha_{1}, \alpha_{3}\right)$ from the orange go to the gray area directly, system (6) enters into chaos through Neimark-Sacker bifurcation. In particular, for $\left(\alpha_{1}, \alpha_{2}\right)$ and $\left(\alpha_{1}, \alpha_{3}\right)$, there is a strange road, from which system enters into chaos through Neimark-Sacker bifurcation and enters into period doubling state again and into chaos through flip bifurcation ultimately. Figure 3(b) can be regarded as the magnified version of the special bifurcation area.

3.3. The Bifurcation and the Largest Lyapunov Exponent. Figure 4 shows the bifurcation diagram with respect to the parameter $\alpha_{1}$ (the price adjustment speed of the traditional channel), while the other adjustment parameters are fixed $\left(\alpha_{2}=0.5\right.$, and $\left.\alpha_{3}=0.5\right)$.

In Figure 4, the bifurcation scenario occurred; if $\alpha_{1}$ is small then there exists a stable equilibrium point (Nash). As we can see from the bifurcation diagram, the Nash equilibrium of price is locally stable for small values of $\alpha_{1}$. As $\alpha_{1}$ increases, the Nash equilibrium of price becomes unstable, and the price process enters into chaos via many period doubling bifurcations. It means that if the bounded rational retailer takes a large value of price adjustment speed in the traditional channel, the system would lead to complex dynamics.

From Figure 4, we can get some stability features of the system via the LLE corresponding to the bifurcation diagram. LLE is the largest Lyapunov exponents, which can express the features of the dynamic system. It is the first time that LLE is equal to 0 , when $\alpha_{1}=0.73$, and at this point the bifurcation takes place. Once LLE $>0$, the system falls into the chaotic state.

Figure 5 shows the basin of attraction with respect to $p_{2}$ and $p_{3}$, when the price game system is in a stable state with $\alpha_{1}=\alpha_{2}=\alpha_{3}=0.5$. The domain of attraction in system (6) is the set of initial price decision variables which can converge to the same attractor. In Figure 5 point $A$ is the attractor for the prices of two Internet channels when the price of offline 


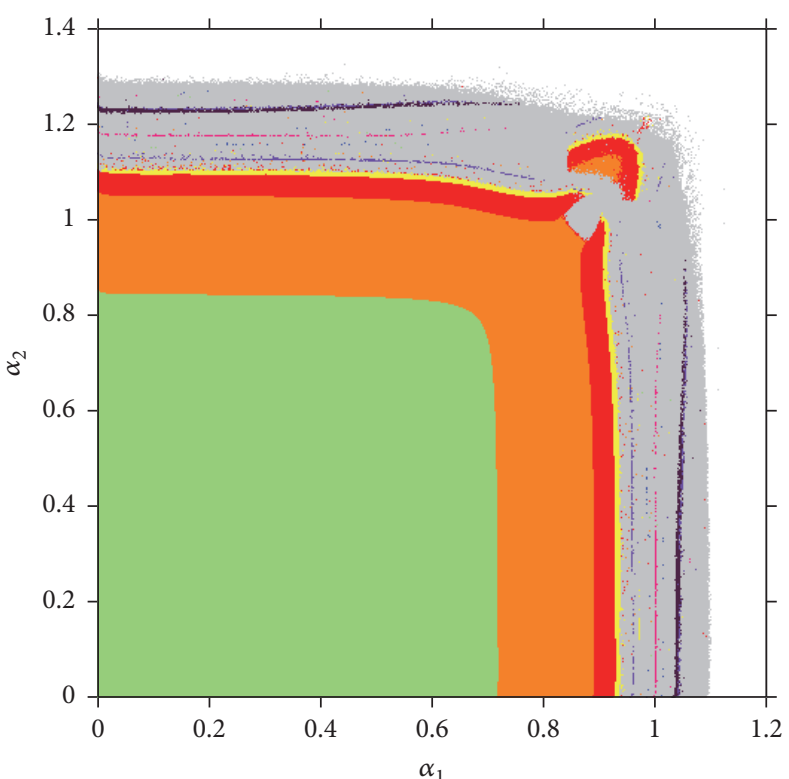

(a) $\alpha_{3}=0.2$

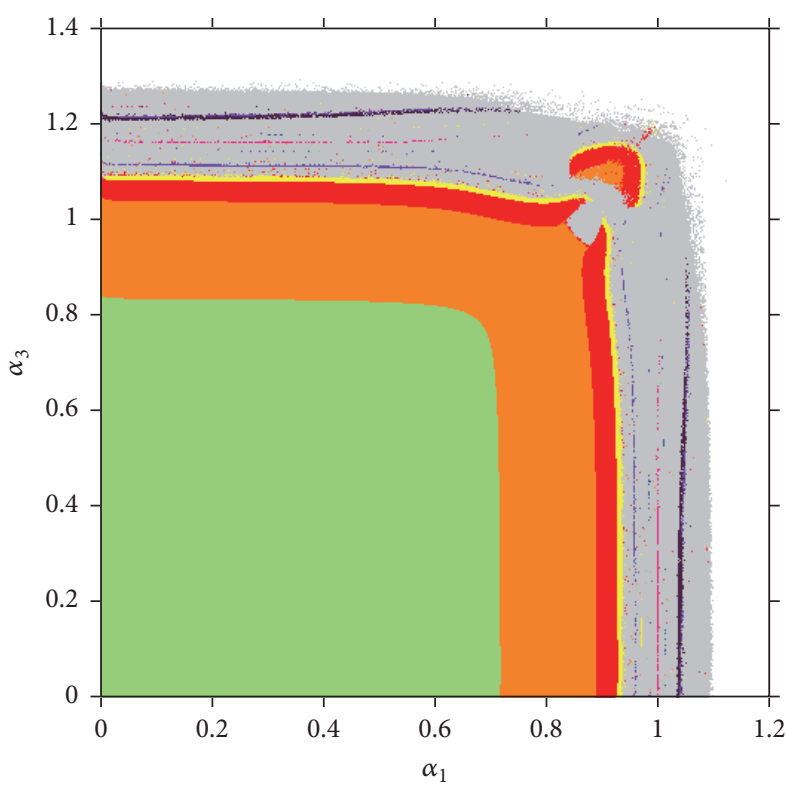

(c) $\alpha_{2}=0.2$

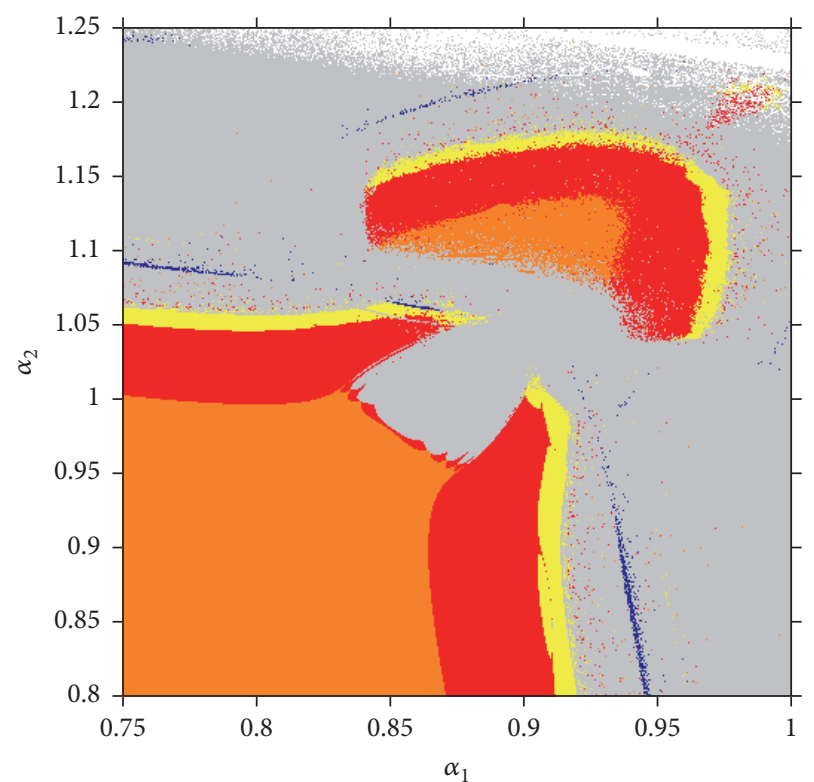

(b) $\alpha_{3}=0.2$

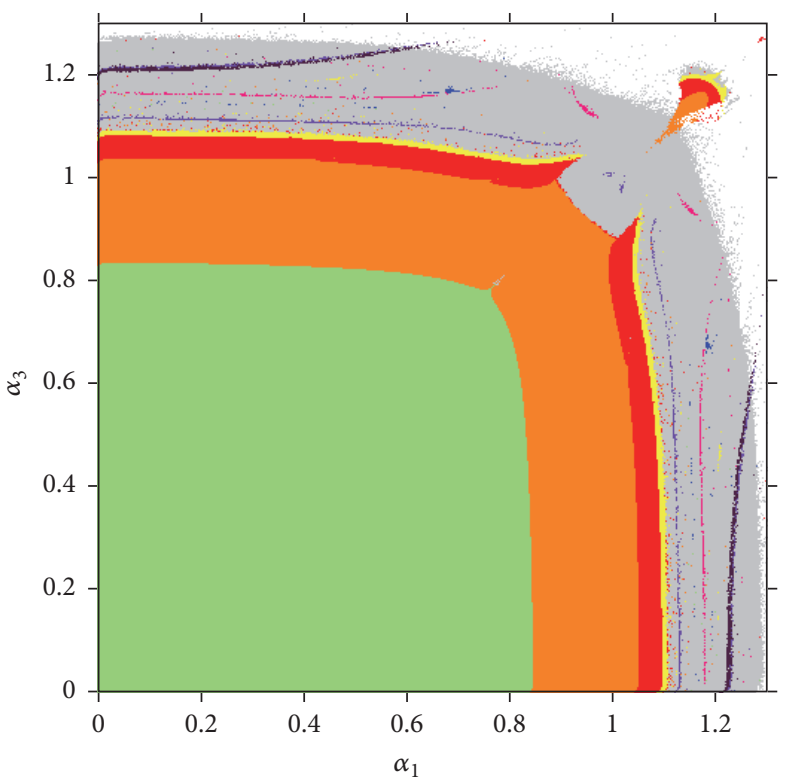

(d) $\alpha_{1}=0.2$

FIgURE 3: 2D parameter basin for periodic cycles output.

retail channel is fixed, and the green region is the feasible basin of attraction for $p_{2}$ and $p_{3}$. Every initial price in the green region can converge to the fixed point $A$. That is to say that, although the system is stable, not every initial price decision can converge to the attractor. Once the initial prices are out of the green region area, system (6) will fall into divergence in the end. So the decisions of the initial prices are very important for every channel of the supply chain. The manufacturer and the retailer should both ensure their prices are not out of the domain of attraction, to keep the system in a long-term stable state.
In Figure 6, the abscissa axis is wholesale price between the manufacture and the retailer, and the axis of ordinates is the price of channel $i$ or the product demand of the supply chain. The black line is a datum line determined by $p=w$. The pink line is the whole product demand of the supply chain. The red line is price of channel 3 , the green line is the channel 2, and the blue line is the channel 1. As the wholesale price increases, prices of all channels will increase; however, the whole demand will decrease. Point $B$, which is the intersection of the black and green line, is the critical point for the change of supply chain structure. The retailer will 

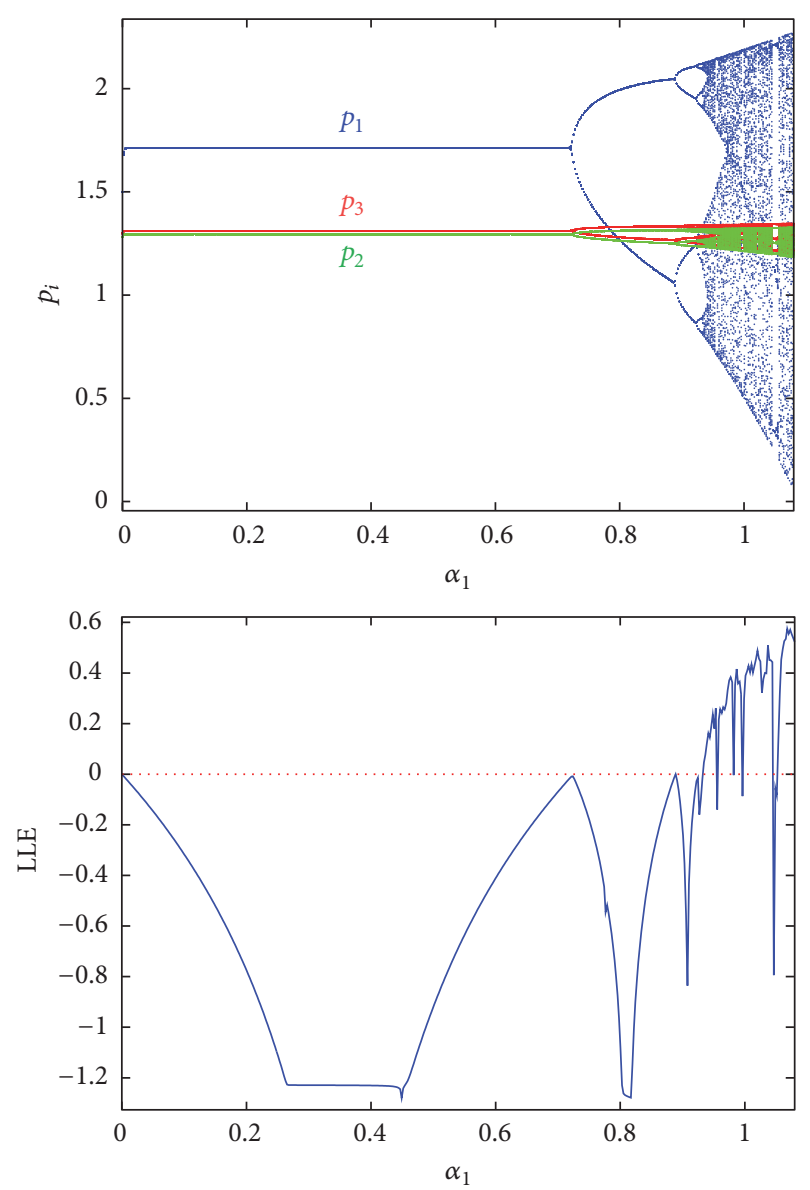

FIGURE 4: Bifurcation diagram and the largest Lyapunov exponent when $\alpha_{2}=0.5$ and $\alpha_{3}=0.5$.

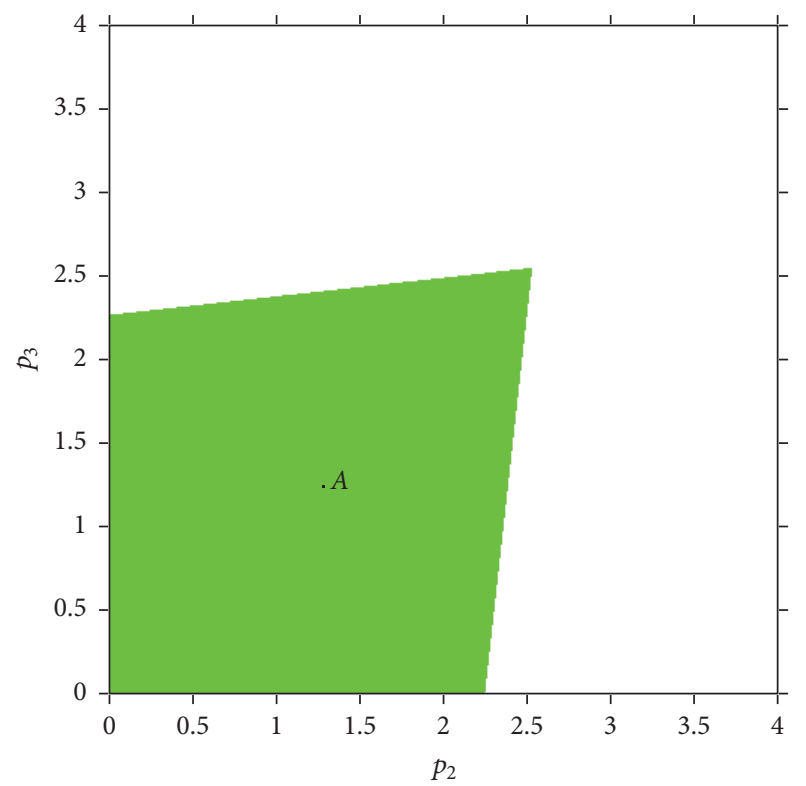

Figure 5: Basin of attraction with respect to $p_{2}$ and $p_{3}$ when $p_{1}=$ 1.5 .

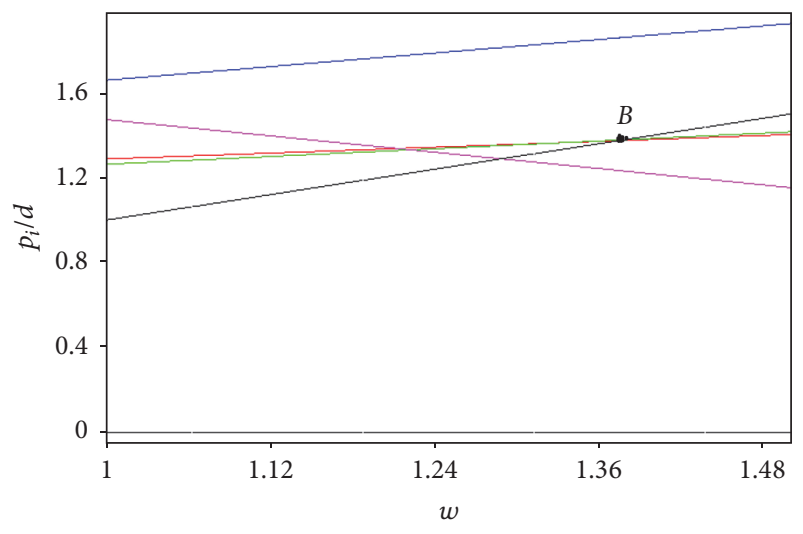

FIgURE 6: The impact of wholesale price on the price equilibrium points and the demands.

keep the wholesale channel although the wholesale price $w$ increases, when the wholesale price is less than $w_{B}$. However, once the wholesale price is more than $w_{B}$, the retailer will not wholesale products from the manufacturer; it will purchase products from the manufacturer's Internet channel directly with a lower price than the wholesale price $w$.

\section{The Bullwhip Effect of Supply Chains}

4.1. The Demand Model. The demand of channel is determined by the its retail price, so we can get the demands according to (1). It is obvious that the price competition will lead to the demand fluctuation. Let the initial prices of all channels be as follows: $p_{1,0}=1.5, p_{2,0}=1.5, p_{3,0}=1.5$.

The demand process of stable and chaotic state is shown in Figure 7. The red line represents the demand of channel $i$ in a stable state $\left(\alpha_{2}=0.8\right)$, and the blue line is the demand of channel $i$ in a chaotic state $\left(\alpha_{2}=1.2\right)$. We can find that the amplitude of demand in a chaotic state is more than that in a stable state. In particular, the demand amplitude of channel 2 is much more than the other two channels in a chaotic state. The demand fluctuation is the source of bullwhip effect [5]. So we investigate the bullwhip effect of the multichannel supply chain in the following sections.

4.2. Replenishment Policy. In this paper we assume that the order-up-to-inventory policy is employed by every channel. The manufacturer and retailer have known their own demand of current period $d_{i, t}$ at the end of period $t$ and estimate their own inventory of period $t+1\left(S_{i, t+1}\right)$ and send the order of period $t\left(q_{i, t+1}\right)$ to the manufacturer. After the lead time $L_{i}$, the retailer receives the products from the manufacturer at the period $t+L_{i}$. The expected inventory of the period $t+1$ is determined by the demand prediction of the lead time.

$$
S_{i, t+1}=\widehat{D}_{i, t+1}^{L_{i}}+z \widehat{\sigma}_{i, t+1}^{L_{i}} \text {. }
$$

Here, $\widehat{\sigma}_{i, t+1}^{L_{i}}$ represents the standard deviation between the actual demand and demand prediction of the lead time. The parameter $z$ is a safety factor, on behalf of the desired service level. In order to deduce a more simple expression 

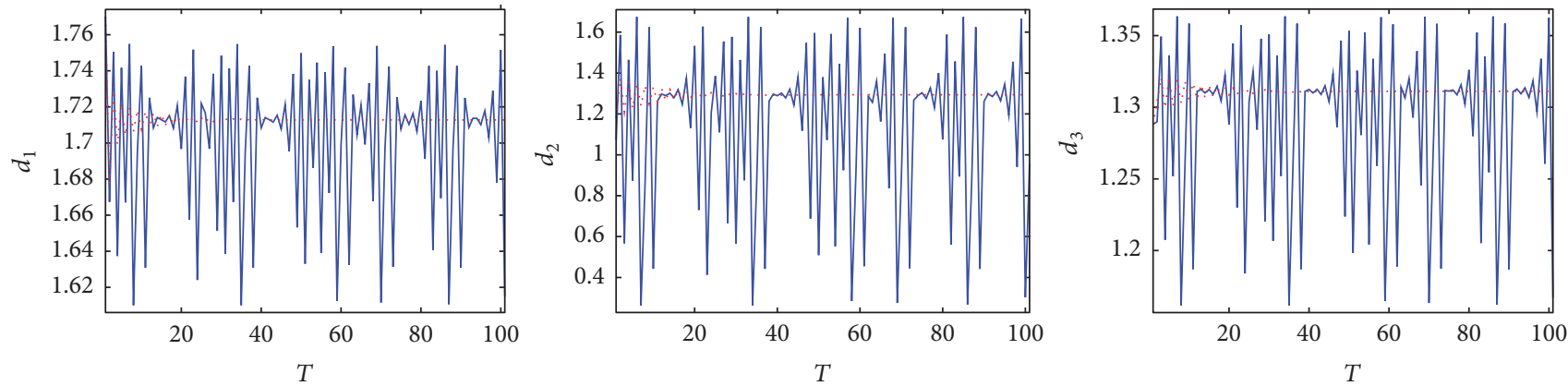

FIGURE 7: The demand process of stable and chaotic state.

for the variance of the orders placed by the retailer to the manufacturer, we assume that the safety factor $z$ is equal to 0 , as this inventory policy is quite common in practice. Taking $z=0$ does not necessarily imply a low service level, because the retailer will often make the lead time parameter $L$ plus one to achieve the desired service level when they take this policy [16].

In order to achieve the desired inventory goal, in the beginning of the period $t+1$, the retailer must send the order $q_{i, t}$ to the manufacturer. After the lead time $L$, the retailer receives the goods at the period $t+L$. Therefore

$$
q_{i, t+1}=S_{i, t+1}-S_{i, t}+d_{i, t}=\widehat{D}_{i, t+1}^{L_{i}}-\widehat{D}_{i, t}^{L_{i}}+d_{i, t} .
$$

The sum of demand prediction of the lead time is as follows:

$$
\widehat{D}_{i, t+1}^{L_{i}}=\widehat{d}_{i, t+1}+\widehat{d}_{i, t+2}+\cdots+\widehat{d}_{i, t+L_{i}}
$$

where $\widehat{d}_{i, t+1}, \ldots, \widehat{d}_{i, t+L-1}, \widehat{d}_{i, t+L}$ denote the corresponding predicted values of $d_{i, t+1}, \ldots, d_{i, t+L-1}, d_{i, t+L}$. In practice, the assumption that $\widehat{d}_{i, t+2} \cdots \widehat{d}_{i, t+L}$ are equal to $\widehat{d}_{i, t+1}$ is very common. Therefore, we can get the order of channel $i$ on the basis of (14):

$$
q_{i, t+1}=\widehat{D}_{i, t+1}^{L_{i}}-\widehat{D}_{i, t}^{L_{i}}+d_{i, t}=L_{i} \widehat{d}_{i, t+1}-L_{i} \widehat{d}_{i, t}+d_{i, t} .
$$

4.3. The Demand Forecast. At the end of period $t$, all channels have known the current price of each channel and can make their price forecast of the next period according to (6), but they cannot know the rival prices of next period; therefore, they just think their opponents take the same price in the next period as the current period. So each channel can give its demand forecast of the next period via (1):

$$
\widehat{d}_{i, t+1}=d_{i, t+1}\left(\widehat{p}_{i, t+1}, p_{j, t}, p_{6-i-j, t}\right),
$$

$$
i, j=1,2,3, j \neq i \text {. }
$$

Here,

$$
\widehat{p}_{i, t+1}=p_{i, t}+\alpha_{i, t} p_{i, t} \frac{\partial u_{i, t}}{\partial p_{i, t}} .
$$

Therefore, using (6), (15), (16), and (17), we can get the order of each channel on the basis of the forecasting price.
The total demand is determined by $d_{t}=d_{1, t}+d_{2, t}+d_{3, t}$, and the total order is determined by $q_{t}=q_{1, t}+q_{2, t}+q_{3, t}$. According to the work of Chen et al. [16], the measure of the bullwhip effect in the multichannel supply chain system can be expressed as

$$
\mathrm{BWE}=\frac{\sigma_{q}^{2} / u_{q}}{\sigma_{d}^{2} / u_{d}} .
$$

4.4. The Bullwhip Effect in Stable and Chaotic State. From the above analysis we can see that the demands of the two retailers experience stable, period doubling, and chaotic state, with the continuous growth of the price adjustment speed of retailers. Considering the demands are price-sensitive and would impact the bullwhip effect, we design a numerical experiment to investigate how the bullwhip effect is affected by the channels' price strategy in different states.

From the figure of bifurcation and the largest Lyapunov exponent, we can find the system is in stable or chaotic state, when the parameters takes values $\alpha_{2}=0.8$ or $\alpha_{2}=1.2$, respectively. In this section, we mainly compare the bullwhip effect of the supply chain on the basis of the demand processes used in Figure 7.

As shown in Figure 8, the red line is the order variance ratio of the whole supply chain in a stable state. The blue line is the order variance ratio of the whole supply chain in the chaotic state. No matter what state the system is, there is bullwhip effect in the multichannel supply chain. After the initial little values, the bullwhip effects in different states decrease gradually and tend to be stable. It is easy to find that the whole supply chain in a chaotic state suffers a larger bullwhip effect than that in a stable state.

4.5. The Impact of the Price Adjustment Speed on Bullwhip Effect. From the above analysis, we may find that the speed of the price adjustment has an important impact on the bullwhip effect of the supply chain. In this section, we intend to investigate the differences of the long-term bullwhip effect when the parameters of the speed of the price adjustment take different values. In particular, we are interested in the interaction of three channel's price strategy.

In Figure 9, we plot 4D map of the bullwhip effect of the whole supply chain using the RGB color map. The drawing standard is that the colors from green to red are 


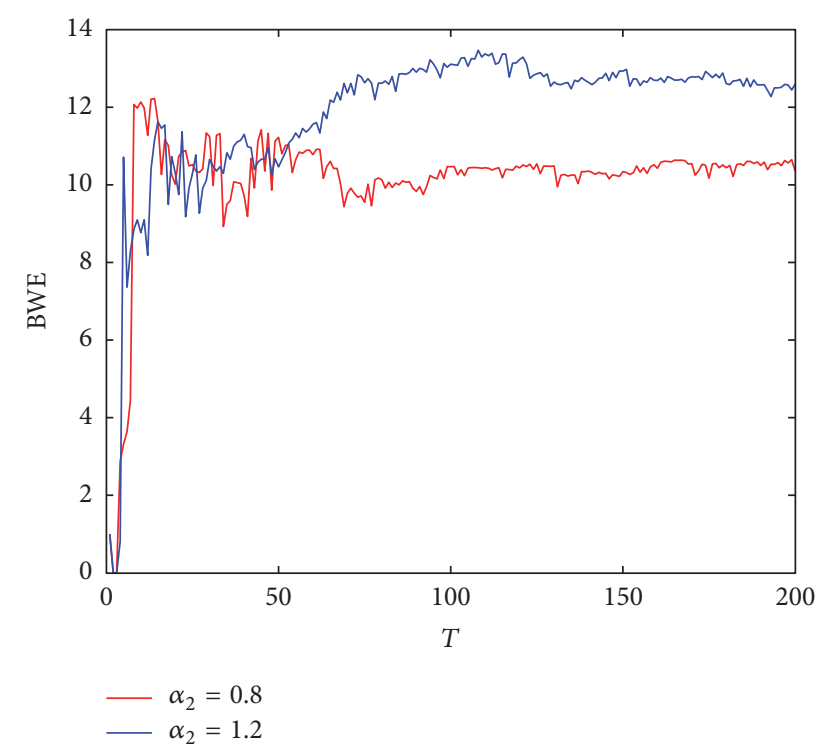

Figure 8: The timing diagram of bullwhip effect in stable and chaotic state.

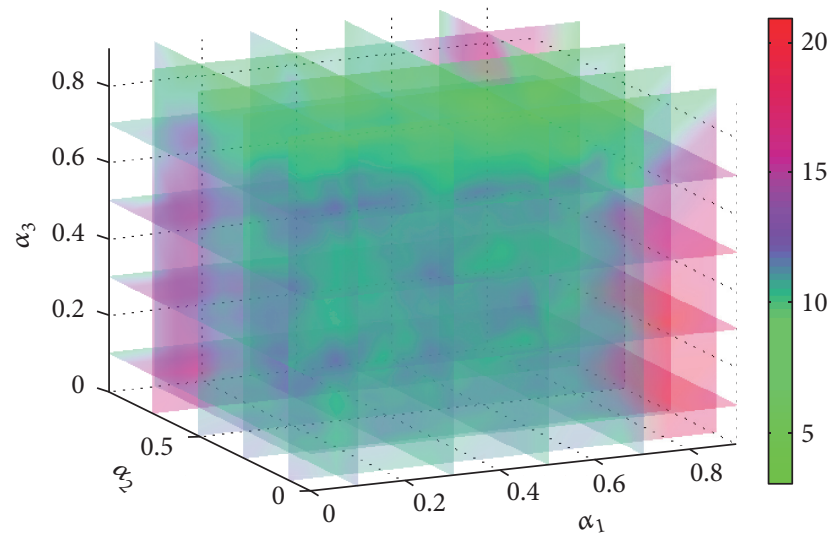

FIgURE 9: The impact of $\alpha_{i}$ on the bullwhip effect.

corresponding to the bullwhip effect from 4 to 20, as shown in the color bar. As shown in Figures 2 and 9, the color changes tell us that the bullwhip effect of supply chain in the stable region is usually less than that out of the stable region. We can find that the bullwhip effect increases as the growth of the retailer's price adjustment speeds $\left(\alpha_{1}\right.$ and $\left.\alpha_{2}\right)$; however, the growth of the manufacturer's price adjustment speeds $\left(\alpha_{3}\right)$ can mitigate the bullwhip effect of the whole supply chain. This result provides a useful managerial insight for the household appliances manufacturer that they can improve their own speed of the price adjustment to reduce the bullwhip effect.

A greater adjustment speed can help retail channels get more quickly the maximum effect and obtain greater longterm profits. But this will also bring greater bullwhip effect; therefore, there must be a suitable adjustment speed for whole supply chain to obtain greater profits and maintain a low bullwhip effect. This suitable adjustment speed must be in a stable state. That is to say, the appliance retail channels cannot adopt a fast and wide range of retail price adjustment strategy or a too cautious price adjustment strategy. They should take a suitable price adjustment speed within their own range to adjust the retail prices in a timely manner according to the price changes of the competitive channels.

A typical example is Midea's home appliance multichannel retail supply chain. Established in 1968, Midea is a publicly listed as (and since July 2016) Fortune 500 company that offers one of the most comprehensive ranges in the home appliance industry. Midea Group sells one kind of rice cooker whose product type is MB-FS406C through Midea Mall which is Midea's only official Internet mall and GOME which is one of mainland China's largest appliance retail chain enterprises. The latter sells this rice cooker via their retail stores and gome.com.cn which is an online shopping mall operated by GOME. The retail price data overserved from three channels shows that the retail price in gome.com.cn changes more frequently with larger amplitude and is lower than the other two channels. This is consistent with the results of our model.

\section{Chaos Control and Mitigation of Bullwhip}

The simulation of bullwhip effect subject to the adjustment speed of price suggests that the bullwhip effect would be mitigated in the equilibrium state compared to the period doubling and chaotic state. From the perspective of supply chain management, firms of supply chain all hope to find some methods to control the chaos and period doubling of the system and lighten their bullwhip effect. In the ways of chaos control, the delayed feedback control method has been widely used in the chaos of supply chain system [9, 17]. In this paper, we propose the delayed feedback control method to control the system. We make the retailer control its Internet channel's adjustment speed when making price decisions with the help of the control parameter $K$. With the controlling, the price decision process of the retailer's Internet channel can be rewritten as

$$
\begin{aligned}
& p_{2, t+1}=p_{2, t}+\alpha_{2} p_{2, t}\left(a \delta_{2}+p_{1, t} \beta+p_{3, t} \eta\right. \\
& \left.-2 p_{2, t}\left(\beta+\eta+\theta_{2}\right)+v w\left(\beta+\eta+\theta_{2}\right)\right)-K\left(p_{2, t+T}\right. \\
& \left.-p_{2, t}\right)
\end{aligned}
$$

where $T$ is the length of the lag time and $K$ is the control parameter. We consider the control of chaos in the system with $T=1$; then we can obtain a new price game system for the two retailers of the supply chain, under the control of channel 2:

$$
\begin{array}{r}
p_{1, t+1}=p_{1, t}+\alpha_{1} p_{1, t}\left(a \delta_{1}+p_{2, t} \beta+p_{3, t} \gamma\right. \\
\left.-2 p_{1, t}\left(\beta+\gamma+\theta_{1}\right)+w\left(\beta+\gamma+\theta_{1}\right)\right),
\end{array}
$$




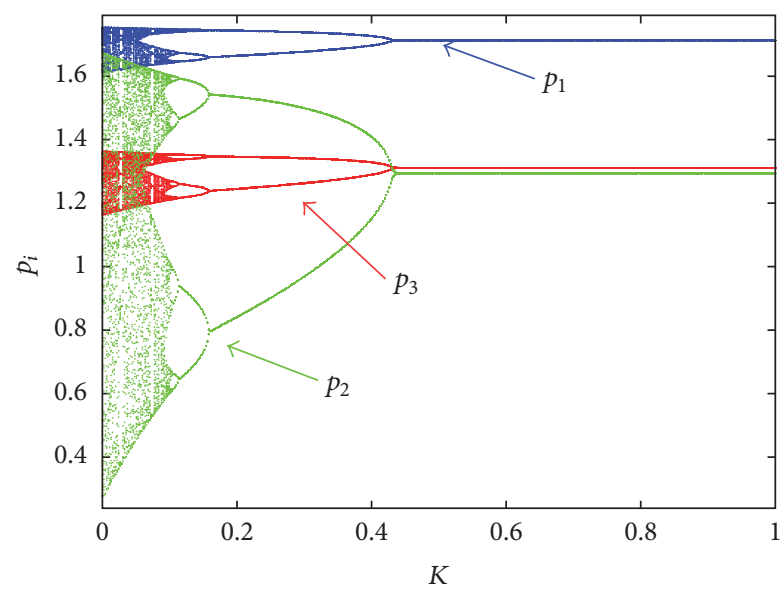

Figure 10: Bifurcation diagram with $\alpha_{1}=\alpha_{3}=0.5$ and $\alpha_{2}=1.2, \mathrm{~K}$ varying from 0 to 1 .

$$
\begin{aligned}
& p_{2, t+1}=p_{2, t}+\alpha_{2} p_{2, t}\left(a \delta_{2}+p_{1, t} \beta+p_{3, t} \eta\right. \\
& \left.-2 p_{2, t}\left(\beta+\eta+\theta_{2}\right)+v w\left(\beta+\eta+\theta_{2}\right)\right)-K\left(p_{2, t+1}\right. \\
& \left.\quad-p_{2, t}\right), \\
& p_{3, t+1}=p_{3, t}+\alpha_{3} p_{3, t}\left(a\left(1-\delta_{1}-\delta_{2}\right)+p_{1, t} \gamma+p_{2, t} \eta\right. \\
& \left.\quad-2 p_{3, t}\left(\gamma+\eta+\theta_{3}\right)+w(\gamma+\eta)+c \theta_{3}\right) .
\end{aligned}
$$

5.1. The Effect of the Control Parameter $K$ on the Price Game System. Based on the above numerical simulation results, we can make the price adjustment parameters $\alpha_{1}=\alpha_{3}=0.5$ and $\alpha_{2}=1.2$ to simulate a chaotic state of system (6). We plot a price bifurcation diagram with respect to $K$. From Figure 10 we can find that under the action of delayed feedback control parameter $K$ the system gradually changes from chaos to period cycles and equilibrium state at last. When $K>0.15$, the system is in a state of twofold period. When $K>0.42$, the competition system enters into a stable state.

\subsection{The Effect of the Control Parameter $K$ on the Bullwhip} Effect. In order to check the effect of the control parameter $K$ on the bullwhip effect, we give a numerical simulation when $\alpha_{1}=\alpha_{3}=0.5$ and $\alpha_{2}=1.2$.

Figure 11 shows the impact of the control parameter $K$ on the bullwhip effect. As the control parameter's value increases from 0 to 0.22 , the bullwhip effect has the upward growth trend. After that the value of bullwhip effect will be steady if the control parameter's value is larger than 0.32. A significant sharp drop of bullwhip effect takes place when the control parameter's value continues to grow from 0.22 to 0.32 .

This shows that the delayed feedback control has achieved a good effect and can effectively alleviate the bullwhip effect the supply chain. The supply chain firms can make the chaotic system controlled by adjusting the control parameter $K$. The retail channel with a strong profit-seeking motive should review the price adjustment at each stage of price decision. If

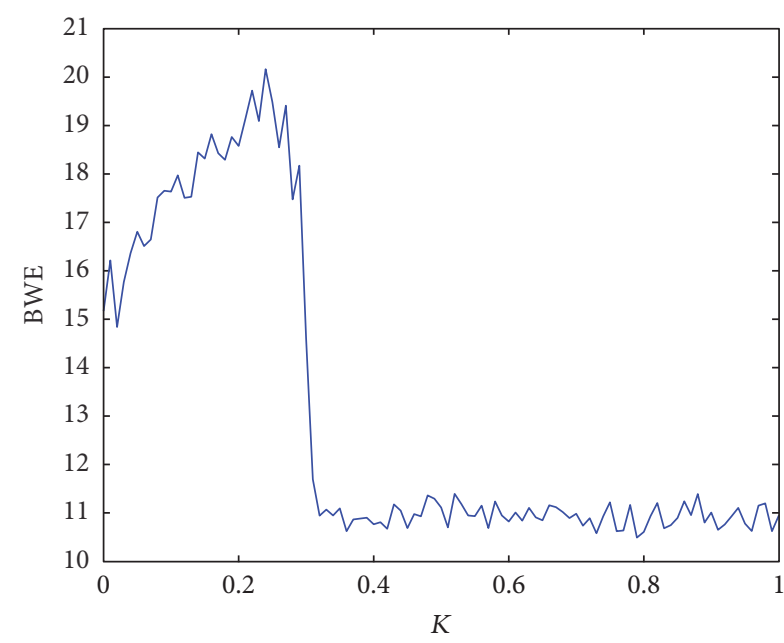

FIgURE 11: Effect of $K$ on the bullwhip effect when $\alpha_{1}=\alpha_{3}=0.5$ and $\alpha_{2}=1.2$.

the price adjustment is too large, the price adjustment should be appropriately reduced, so that the system can be stabilized.

\section{Conclusions}

This paper focuses on the dynamic pricing game of household appliance supply chain with more than one Internet channel and investigates the nonlinear characteristics of the multichannel household appliance, and we explore how their price adjustment speeds affect the stability of the system and the bullwhip effect of the whole supply chain.

This paper constructs a model of multichannel household appliance supply chains including a retailer with and a manufacturer with an Internet channel. All channels take price as the competitive variable and make bounded rational decision in order to obtain the optimal profit or much more market share. This paper studies the complex characteristics caused by the price competition in multichannel household appliance supply chains. Considering price competition often leads to the demand and order fluctuation, we also investigate the bullwhip effect of the multichannel supply chains on the basis of the order-up-to-inventory policy. From the numerical simulation, we find a system in a chaotic state will suffer larger bullwhip effect than a stable system, and a large price adjustment speed in the manufacturer's Internet channel is helpful to mitigate the bullwhip effect. Our results provide useful managerial inspirations for the household manufacturer who operates an Internet retail channel and retailers who have adopted a multichannel strategy. Firstly, both the household appliance manufacturer and its retailer should manage their retail channel with a suitable price adjustment speed in the stable region, and each of their pricing decisions cannot exceed the domain of attraction. Secondly, if the manufacturer wants to mitigate the bullwhip effect, they can adopt a more radical pricing strategy in their Internet channel. Thirdly, the feedback control on the retail channel with a strong profit-seeking motive is an effective 
method to control the chaos of price game system and mitigate the bullwhip effect of the supply chain. The price adjustment should be reviewed and be appropriately reduced if the price adjustment is too large.

\section{Appendix}

The profit functions of three channels are as follows:

$$
\begin{aligned}
\pi_{1} & =d_{1}\left(p_{1}-w\right)=\left(\theta_{1} a-s_{1} p_{1}+\beta p_{2}+\gamma p_{3}\right)\left(p_{1}\right. \\
& -w), \\
\pi_{2} & =\left(\theta_{2} a+\beta p_{1}-s_{2} p_{2}+\eta p_{3}\right)\left(p_{2}-w\right), \\
\pi_{3} & =\left(\left(1-\theta_{1}-\theta_{2}\right) a+\gamma p_{1}+\eta p_{2}-s_{3} p_{3}\right)\left(p_{3}-c\right) \\
& +\left(\theta_{1} a-s_{1} p_{1}+\beta p_{2}+\gamma p_{3}+\theta_{2} a+\beta p_{1}-s_{2} p_{2}\right. \\
& \left.+\eta p_{3}\right)(w-c) .
\end{aligned}
$$

According the assumption about the utility of three channels, their functions can be expressed as follows:

$$
\begin{aligned}
& u_{1}=\pi_{1}=d_{1}\left(p_{1}-w\right), \\
& u_{2}=v \pi_{2}+(1-v) e_{2}=v d_{2}\left(p_{2}-w\right)+(1-v) d_{2} p_{2}, \\
& u_{3}=\pi_{3}=d_{3}\left(p_{3}-c\right)+\left(d_{1}+d_{2}\right)(w-c) .
\end{aligned}
$$
form:

So, their marginal utility can be written in the following

$$
\begin{aligned}
\frac{\partial u_{1}}{\partial p_{1}}= & a \delta_{1}+p_{2} \beta+p_{3} \gamma-2 p_{1}\left(\beta+\gamma+\theta_{1}\right) \\
& +w\left(\beta+\gamma+\theta_{1}\right), \\
\frac{\partial u_{2}}{\partial p_{2}}= & a \delta_{2}+p_{1} \beta+p_{3} \eta-2 p_{2}\left(\beta+\eta+\theta_{2}\right) \\
& +v w\left(\beta+\eta+\theta_{2}\right), \\
\frac{\partial u_{3}}{\partial p_{3}}= & a\left(1-\delta_{1}-\delta_{2}\right)+p_{1} \gamma+p_{2} \eta \\
& -2 p_{3}\left(\gamma+\eta+\theta_{3}\right)+w(\gamma+\eta)+c \theta_{3} .
\end{aligned}
$$

\section{Key Notations}

\section{Variables}

$d_{i, t}$ : The market demand of channel $i(i=1,2,3)$ at time $t$

$p_{i, t}$ : The price of channel $i(i=1,2,3)$ at time $t$

$q_{t}$ : The order of the whole channels

$q_{i, t}$ : The order quantity of channel $i$

$S_{i, t}$ : The order-up-to point of channel $i$

$\widehat{D}_{t}^{L}$ : The estimate vector of the lead time demand

$\pi_{i}$ : The expected profit of the $i$ th channel.

\section{Parameters}

$c$ : The unit cost of the product

$w$ : The wholesale price $\alpha_{i}$ : The price adjustment speed of channel $i$

$a$ : The possible largest market demand

$\delta_{i}$ : The initial proportion of the market share of channel $i$

$b_{i}$ : The price sensitivity of consumers for channel $i$

$\beta$ : The price-gap sensitivity of consumers between channel 1 and channel 2

$\gamma$ : The price-gap sensitivity of consumers between channel 1 and channel 3

$\eta$ : The price-gap sensitivity of consumers between channel 2 and channel 3

$E$ : The stable set of the price decision-making coefficients

$L_{i}$ : The lead time of channel $i$

$z$ : The safety factor.

\section{Competing Interests}

The authors declare no conflict of interests regarding the publication of this paper.

\section{Acknowledgments}

The research was supported by the National Natural Science Foundation of China (nos. 71571131 and 61273231) and Doctoral Fund of Ministry of Education of China (Grant no. 20130032110073).

\section{References}

[1] W. Wang, G. Li, and T. C. E. Cheng, "Channel selection in a supply chain with a multi-channel retailer: the role of channel operating costs," International Journal of Production Economics, vol. 173, pp. 54-65, 2016.

[2] R. Yan, "Profit sharing and firm performance in the manufacturer-retailer dual-channel supply chain," Electronic Commerce Research, vol. 8, no. 3, pp. 155-172, 2008.

[3] G. G. Cai, "Channel Selection and Coordination in DualChannel Supply Chains," Journal of Retailing, vol. 86, no. 1, pp. 22-36, 2010.

[4] X. Chen and X. Wang, "Free or bundled: channel selection decisions under different power structures," Omega, vol. 53, pp. 11-20, 2015.

[5] H. L. Lee, V. Padmanabhan, and S. Whang, "Information distortion in a supply chain: the bullwhip effect," Management Science, vol. 43, no. 4, pp. 546-558, 1997.

[6] K. Melis, K. Campo, E. Breugelmans, and L. Lamey, "The impact of the multi-channel retail mix on online store choice: does online experience matter?" Journal of Retailing, vol. 91, no. 2, pp. 272-288, 2015.

[7] M. Liu, E. Cao, and C. K. Salifou, "Pricing strategies of a dual-channel supply chain with risk aversion," Transportation Research Part E: Logistics and Transportation Review, vol. 90, pp. 108-120, 2016.

[8] T. Li and J. Ma, "Complexity analysis of the dual-channel supply chain model with delay decision," Nonlinear Dynamics, vol. 78, no. 4, pp. 2617-2626, 2014

[9] J. Ma and L. Xie, "The comparison and complex analysis on dual-channel supply chain under different channel power 
structures and uncertain demand," Nonlinear Dynamics, vol. 83, no. 3, pp. 1379-1393, 2016.

[10] E. C. Özelkan and M. Çakanyıldırım, "Reverse bullwhip effect in pricing," European Journal of Operational Research, vol. 192, no. 1, pp. 302-312, 2009.

[11] X. Zhang and G. J. Burke, "Analysis of compound bullwhip effect causes," European Journal of Operational Research, vol. 210, no. 3, pp. 514-526, 2011.

[12] Y. Ma, N. Wang, A. Che, Y. Huang, and J. Xu, "The bullwhip effect under different information-sharing settings: a perspective on price-sensitive demand that incorporates price dynamics," International Journal of Production Research, vol. 51, no. 10, pp. 3085-3116, 2013.

[13] Y. Ma, N. Wang, Z. He, J. Lu, and H. Liang, "Analysis of the bullwhip effect in two parallel supply chains with interacting pricesensitive demands," European Journal of Operational Research, vol. 243, no. 3, pp. 815-825, 2015.

[14] H. Wang and J. Ma, "Complexity analysis of a cournotbertrand duopoly game model with limited information," Discrete Dynamics in Nature and Society, vol. 2013, Article ID 287371, 6 pages, 2013.

[15] Y. Guo and J. Ma, "Research on game model and complexity of retailer collecting and selling in closed-loop supply chain," Applied Mathematical Modelling, vol. 37, no. 7, pp. 5047-5058, 2013.

[16] F. Chen, Z. Drezner, J. K. Ryan, and D. Simchi-Levi, "Quantifying the bullwhip effect in a simple supply chain: the impact of forecasting, lead times, and information," Management Science, vol. 46, no. 3, pp. 436-443, 2000.

[17] J. Ma and J. Zhang, "Price game and chaos control among three oligarchs with different rationalities in property insurance market," Chaos, vol. 22, no. 4, Article ID 043120, 2012. 


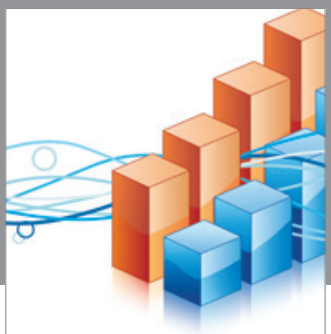

Advances in

Operations Research

vatem alat4

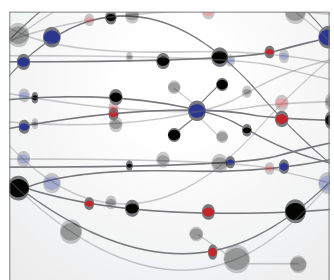

\section{The Scientific} World Journal
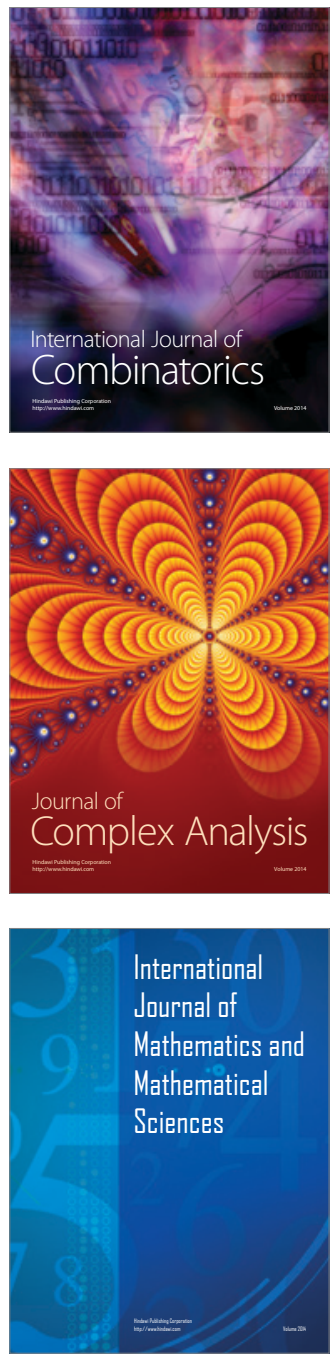
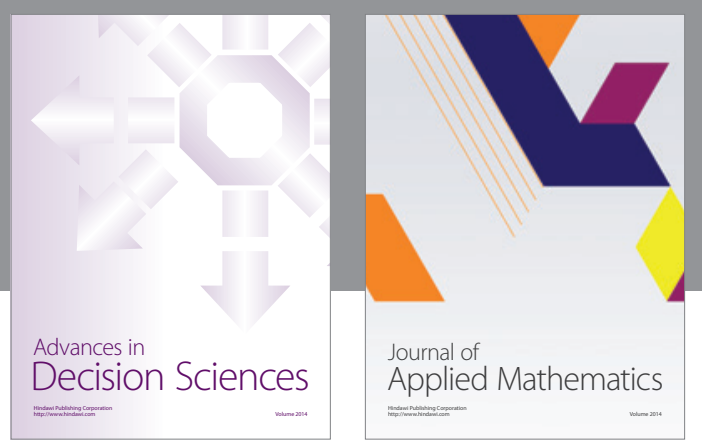

Algebra

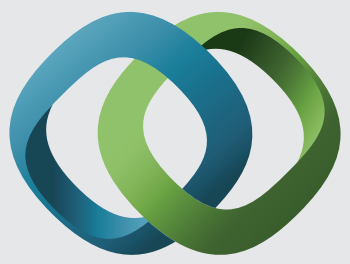

\section{Hindawi}

Submit your manuscripts at

https://www.hindawi.com
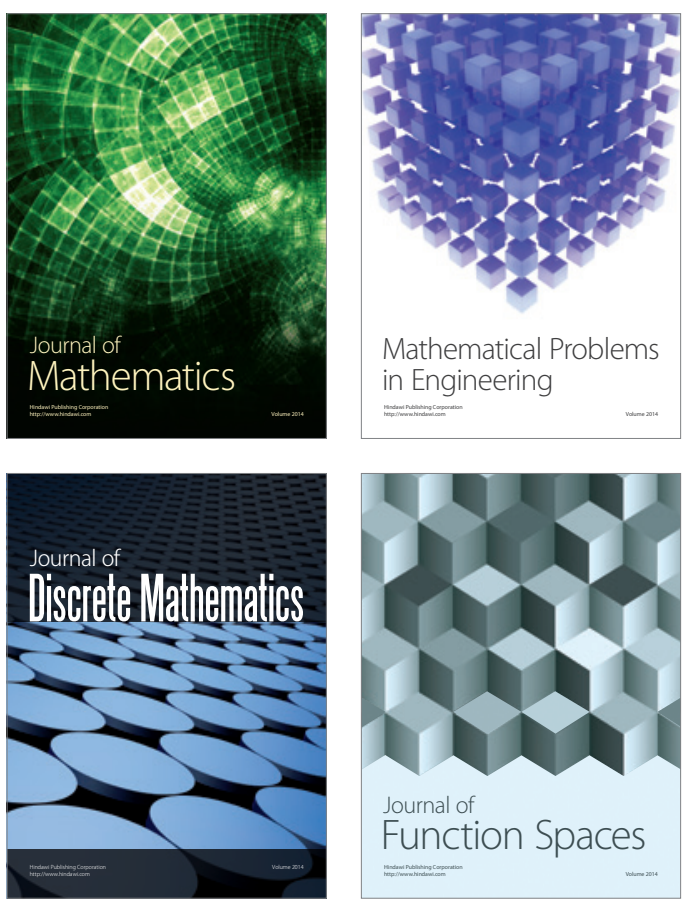

Mathematical Problems in Engineering
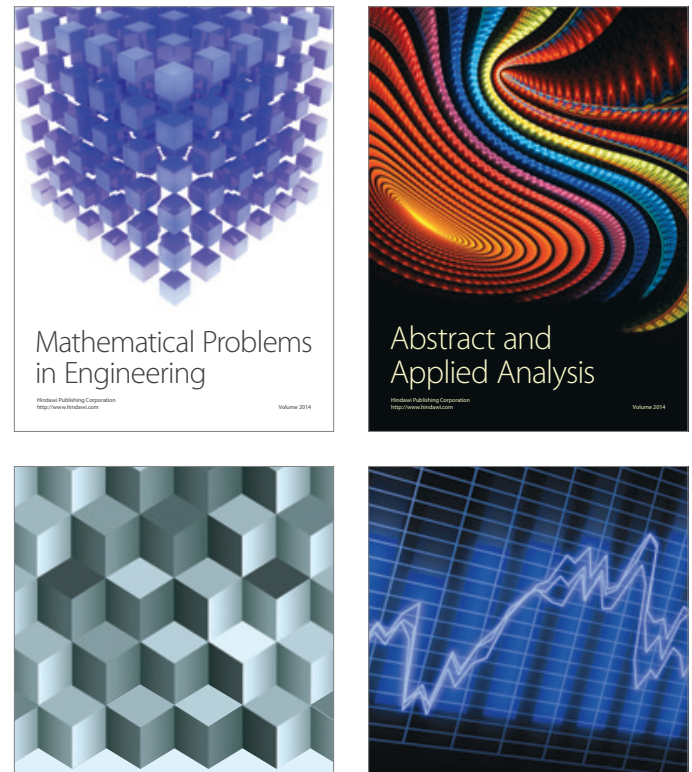

Journal of

Function Spaces

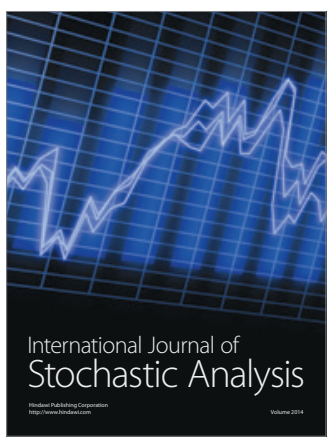

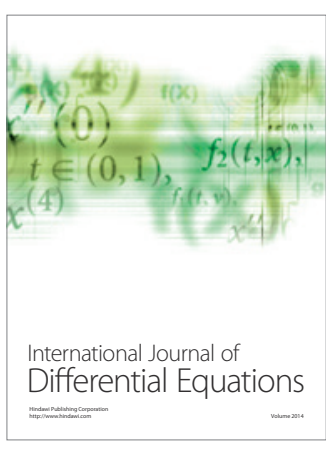
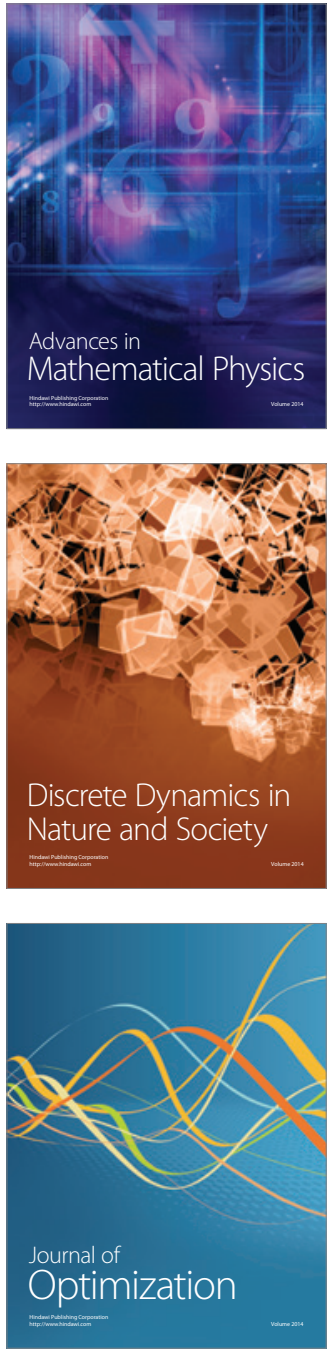